and substantia nigra. The neurobiology has in fact been demonstrated in the case of a 17-year-old boy manifesting reduction of obsessive slowness in response to fluoxetine, with return to normality of decreased tracer deposition on brain scanning in the basal ganglia and adjacent temporal lobe of the right hemisphere, in which the metabolic rate is lower in males (Friedman, 1990). This neurobiology is also demonstrated by Parkinson's disease of the right hemisphere manifested by elongated pauses (Friedman, 1987). Neural circuits concerned with acting on decisions and completing the ensuing behavioural sequences may be more sensitive to damage in males. This is suggested both by frontal damage, which may cause an inability to reactivate previously generated intentions, after a delay, when they are not directly signalled by the stimulus situation (Shallice \& Burgess, 1991), and by the fact that delay-dependent speeding of reaction time, reflecting motor readiness, is abolished by depletion of dopamine (Brown \& Robbins, 1991) subserving the mesocorticolimbic system (Csernansky et al, 1991).

Brown, V. J. \& Robbins, T. W. (1991) Simple and choice reaction time performance following unilateral striatal dopamine depletion in the rat: impaired motor readiness but preserved response preparation. Brain, 114, 513-525.

Csernansky, J. G., Murphy, G. M. \& Faustman, W. O. (1991) Limbic/mesolimbic connections and the pathogenesis of schizophrenia. Biological Psychiatry, 30, 383-400.

Friedman, E. H. (1987) More on Hitler and Parkinson's disease. New' England Journal of Medicine, 316, 114.

- (1990) Dopamine and obsessive symptom expression. Neuropsychiairy. Neuropsychology and Behavioral Neurology, 3, 313.

Shallice, T. \& Burgess, P. W. (1991) Deficits in strategy application following frontal lobe damage in man. Brain, 114, 727-741.

1831 Forest Hills Boulevard

ERNEST H. FRIEDMAN

East Cleveland

OH 44112-4313, USA

\section{Musical hallucinations triggered by clomipramine?}

SIR: We would like to report a case of musical hallucinations similar to other cases recently reported in this journal (Fenton \& McRae, 1989; Berrios, 1990; McLoughlin, 1990), but associated with the use of clomipramine.

Case report. A 67-year-old widowed female was referred for consultation about her anxiety and depressive symptoms which had gradually become incapacitating over the previous five years. Her medical history included asthma since childhood, deteriorating eyesight due to uveitis, cataract and trachoma, and a decreasing ability to discriminate between both sounds and words, notably over the previous three years. ENT consultation and audiometric tests showed a slight deafness at high frequencies, worse on the left. She reported childhood experiences of sudden inversion of visual images, as if she were looking in a mirror. A neurological evaluation including CT scan, clinical EEG, and routine laboratory tests was normal. A diagnosis of panic/agoraphobia with secondary depressive symptoms was made, and she was prescribed clomipramine in increasing dosage up to $50 \mathrm{mg} /$ day. Within two weeks her panic attacks had ceased. During week three the dosage was raised to $75 \mathrm{mg} /$ day because of residual depressive symptoms. She felt sedated and drowsy for two days, and then noticed that she was hearing music: the national anthem, hallelujahs, and other choral pieces. The sounds were so clear and loud that she thought they were coming from the street. She soon realised that the music was coming from her own ears. In the beginning the experience was pleasant and sometimes she could select the music at will. It was always familiar songs she herself had sung in a chorus years before. Sometimes music heard during the day would return at bedtime. Within days, the experience became distressing. The music became louder and out of control, speeding up or scratching like a damaged record. The dosage of her clomipramine was reduced to $35 \mathrm{mg} /$ day, and this led to a reduction in volume. She remained for a year on this dosage. She continued to work and, living alone, was competent in her activities. She had no panic, phobic avoidance or depression. The music remained, low in volume, and pleasant. A reduction in her clomipramine to $10 \mathrm{mg} /$ day led to a relapse of panic and breathlessness. Even at this low dosage she continued to hear the music but only in quiet places. The dosage was first raised to $30 \mathrm{mg}$ and then kept at $10 \mathrm{mg} /$ day. She has continued to have tolerable musical hallucinations.

Musical hallucinations ( $\mathrm{MH}$ ) are a rare phenomenon, the actual incidence of which is unknown. They can be associated with a variety of clinical situations such as diseases of the ear, brain tumours, depression, alcohol and drugs. Typically, $\mathrm{MH}$ have been associated with marked hearing loss, advanced age, and female sex. The hallucinations are usually vivid, pleasant, and often consist of familiar hymns and songs. The mechanism involved in the production of these hallucinations is unclear. MH may result from a combination of peripheral ("sensory-deprivation") and central nervous system dysfunction. It is conceivable that its production involves memory retrieval (Keshavan et al, 1988; Fenton \& McRae, 1989; Berrios, 1990).

The temporal association with use of clomipramine reported in this case, and its apparent dose relationship suggest a direct pharmacological effect, perhaps on the right temporal lobe (Berrios, 1990), although the brain area of origin of $\mathrm{MH}$ is still controversial (Keshavan et al, 1988). Anticonvulsants may attenuate $\mathrm{MH}$ in some, but not all, patients (Keshavan et al, 1988; Berrios, 1990). This patient's increasing 
sensory loss might have made her particularly vulnerable to the seizure threshold lowering effects of clomipramine. To our knowledge there has been only one other report that $\mathrm{MH}$ began in two patients shortly after the initiation of an antidepressant (amtriptyline $75 \mathrm{mg}$ and nortriptyline $75 \mathrm{mg}$ ) (Wegel et al, 1989).

Berrios, G. E. (1990) Musical hallucinations. A historical and clinical study. British Journal of Psychiatry, 156, 188-194.

Fenton, G. W. \& MCRAE, D. A. (1989) Musical hallucinations in a deaf elderly woman. British Journal of Psychiatry, 155, 401-403.

Keshavan, M. S., Kahn, E. M., Brar, J. S. (1988) Musical hallucinations following removal of a right frontal meningioma. Journal of Neurology, Neurosurgery \& Psychiatry, 51, 1235-1236.

MCLoughuIN, I. (1990) Musical hallucinations. British Journal of Psychiatry, 156, 452.

Wegel, S. P.. Burke, W. J. \& Holemon, D. (1989) Musical hallucinations. The sounds of silence? Journal of the American Geriatric Society, 37, 163-166.

Institute of Psychiatry

H. P. VAllada

Genetics Section

De Crespigny Park

London SE5 8 AF

Departamento de Psiquiatrica

Universidade de Sao Paulo, Brazil

V. GENTIL

\section{Crossover reaction between haloperidol and amoxapine for NMS}

SIR: Neuroleptic malignant syndrome (NMS) is a potentially fatal complication of neuroleptic treatment. This syndrome has also been reported in association with antidepressants (Baca \& Martinelli, 1990; Halman \& Goldbloom, 1990). We report a crossover reaction between a neuroleptic (haloperidol) and an antidepressant (amoxapine), which has not previously been reported.

Case report. The patient was a 68-year-old woman (body weight $41 \mathrm{~kg}$ ) suffering from major depression with psychotic features. Nine days before admission, amitriptyline $(30 \mathrm{mg} / \mathrm{day})$ was introduced. On admission, the prescription was switched to haloperidol $1 \mathrm{mg}$ and mianserin $10 \mathrm{mg}$, daily. Haloperidol was gradually increased, and from the 12 th day of admission the daily dose was fixed to $10 \mathrm{mg}$. On the 17th day, the following clinical symptoms and laboratory findings were observed: stupor, lead-pipe muscle rigidity, a fever of $38.9^{\circ} \mathrm{C}$ axillary, autonomic disturbances (hypertension, tachycardia, profuse diaphoresis, and dysuria), an elevated serum creatine phosphokinase (CPK) level (640 IU/l: normal value, 30-170 IU/l), leucocytosis $\left(12100 / \mathrm{mm}^{3}\right)$, and a low serum iron level $(14 \mu \mathrm{g} / \mathrm{dl}$ : normal value, $50-170 \mu \mathrm{g} / \mathrm{dl}$ ). A diagnosis of NMS was made, and all medication was discontinued. All symptoms of NMS disappeared by dantrolene and subsequent levodopa treat- ment. During the next 14 months, several antidepressants, such as mianserin (10-20 mg/day, 23 weeks), maprotiline (10-30 mg/day, 4 weeks), and clomipramine $(10-50 \mathrm{mg} /$ day, 4 weeks) were prescribed with no significant improvement in depression. Finally, amoxapine $(25 \mathrm{mg} /$ day) was introduced. On the 21 st day, the development of NMS was unequivocal. The following clinical symptoms and laboratory findings were observed: stupor, lead-pipe muscle rigidity, a fever of $39.0^{\circ} \mathrm{C}$, autonomic disturbances, an elevated serum CPK level (1090 IU/l), and a low serum iron level $(10 \mu \mathrm{g} / \mathrm{dl})$. Amoxapine was withdrawn, and all symptoms of NMS disappeared with levodopa treatment. Blood analysis including serum iron level was normal except in the NMS episodes.

Some investigators have postulated facilitative roles of increased noradrenergic (Baca \& Martinelli, 1990) or serotonergic (Halman \& Goldbloom, 1990) activity in the pathogenesis of NMS. However, in the present patient, who was apparently very susceptible to NMS, of the antidepressants prescribed, only amoxapine, which has a significant dopaminergic blockade property (Cohen et al, 1982), caused NMS, while the remaining antidepressants which all potentiate noradrenergic and/or serotonergic activities did not. Thus, the present report suggests that dopaminergic blockade sufficiently explains the pathogenesis of NMS (Otani et al, 1991), and that facilitative roles of noradrenalin and serotonin are minute. Although the cause(s) of dramatic fall in serum iron level in NMS remains obscure, this may further facilitate hypodopaminergic states as suggested by Rosebush \& Stewart (1989), since iron deficiency diminishes central dopaminergic activity.

BACA, L. \& MARTINELLI, L. (1990) Neuroleptic malignant syndrome: a unique association with a tricyclic antidepressant. Neurology: 40, 1797-1798.

Cohen, B. M., Harkis, P. Q., Altesman, R. I., el al (1982) Amoxapine: neuroleptic as well as antidepressant? American Journal of Psychiatry, 139, 1165-1167.

Halman, M. \& Goldbloom, D. S. (1990) Fluoxetine and neuroleptic malignant syndrome. Biological Psychiatry, 28, 518-521.

Otani, K., Horiuch, M., Kondo, T., et al (1991) Is the predisposition to neuroleptic malignant syndrome genetically transmitted? British Journal of Psychiatry, 158, 850-853.

RosebUSH, P. \& STEWART, T. (1989) A prospective analysis of 24 episodes of neuroleptic malignant syndrome. American Journal of Psychiatry, 146, 717-725.

\section{KOICHI OTANI KazUO MiHARA MOTOHIRO OKADA Sunao Kaneko} Department of Neuropsychiatry Hirosaki University Hospital Hirosaki 036, Japan 